\section{International Scientific Journal Theoretical \& Applied Science}

p-ISSN: 2308-4944 (print) $\quad$ e-ISSN: 2409-0085 (online)

Year: $2016 \quad$ Issue: 9 Volume: 41

Published: $30.09 .2016 \quad$ http://T-Science.org
Umid Qurbanovich Mamayusupov Senior research scientist Assistant of the department "Philosophy" The Nizami Tashkent State Pedagogical University conference_2012@list.ru

SECTION 30. Philosophy.

\title{
THE SUBJECT-OBJECT ACTIVITY IN THE PROCESS OF SCIENTIFIC PREDICTION IN THE DEVELOPMENT OF THEORETICAL AND EMPIRICAL KNOWLEDGE
}

\begin{abstract}
This article discusses some of the features of the subject-object activity in the cognitive process as a whole and in the process of scientific prediction, in particular. The article focuses on the consideration of some of the concepts related to research in the field of scientific prediction relating to the influence of this phenomenon on the development of empirical and theoretical knowledge.

Key words: subject of knowledge, object of knowledge, scientific and knowledge concepts, scientific prediction, verifiability, falsificationism, critical rationalism, empirical knowledge, theoretical knowledge.

Language: Russian

Citation: Mamayusupov UQ (2016) THE SUBJECT-OBJECT ACTIVITY IN THE PROCESS OF SCIENTIFIC PREDICTION IN THE DEVELOPMENT OF THEORETICAL AND EMPIRICAL KNOWLEDGE. ISJ Theoretical \& Applied Science, 09 (41): 128-131.

Soi: http://s-o-i.org/1.1/TAS-09-41-19 Doi: crossef http://dx.doi.org/10.15863/TAS.2016.09.41.19

\section{СУБЪЕКТ-ОБЬЕКТНАЯ ДЕЯТЕЛЬНОСТЬ В ПРОЦЕССЕ НАУЧНОГО ПРЕДВИДЕНИЯ В РАМКАХ РАЗВИТИЯ ТЕОРЕТИЧЕСКИХ И ЭМПИРИЧЕСКИХ ЗНАНИЙ}

Аннотация: В данной статье рассматриваются некоторые особенности субъект-объектной деятельности в познавательном процессе в целом и в процессе научного предвидения, в частности. В статье основное внимание уделяется рассмотрению некоторых концепций, связанных с исследованиями 8 области научного предвидения, относящихся к влиянию этого феномена на развитие эмпирических и теоретических знаний.

Ключевые слова: субъект познания, объект познания, научно-познавательные концепции, научное предвидение, верифицируемость, фальсификационизм, критический рационализм, эмпирическое знание, теоертическое знание.
\end{abstract}

\section{Introduction}

Научное предвидение в настоящее время играет важную роль в развитии научного знания. И это закономерно. Ведь эффективность умелого использования и верного расчёта предвидения трудно переоценить. Научное предвидение успешно реализуется в развитии не только теоретических, но и практических знаний. Познание в целом сегодня немыслимо без возможностей научного предвидения.

Соотношение субъекта и объекта научного предвидения особо значимо для раскрытия места предвидения в развитии научного знания на всех его уровнях.
В самом общем виде объект предвидения представляет то, на что нацелен процесс предвидения. как полагает ряд авторов - «научное предвидение как форма теоретического освоения мира и вид духовного производства представляет собой субъективное отражение объективного мира и закономерностей его развития» [3-5].

Поскольку вся природа представляет собой совокупность вещей, взаимодействующих друг с другом и находящихся благодаря этому в движении, изменении и развитии, то свойство предметов и явлений материального мира проявляются в их взаимодействии друг с другом, следовательно и отражение, формой которого 
является предвидение есть, лишь одна из разновидностей этого всеобщего взаимодействия.

Отражение как результат взаимодействия представляет собой совокупность изменений, адекватных внешнему воздействию, например, след на песке соответствует ступне ног; зеркальное отражение совпадает с отображаемым предметом. Имеется определённое сходство процесса отражения с причинно-следственными отношениями объектов. Как известно, причинность - это генетическая связь явлений, когда одно явление, называемое причиной, при наличии определённых условий неизбежно попрождает, вызывает к жизни другое явление, называемое следствием.

\section{Materials and Methods}

Как отмечала учёный из Узбекистана К.И.Иванова к существенным признакам причинной связи можно отнести следующие: её необходимый и объективный характер; пространственная непрерывность (всякое следствие порождает новое следствие) и временная непрерывность (нет беспричинных явлений) причинно-следственных цепей [6].

Пространственная и временная непрерывность причинно-следственных отношений, - по мнению исследователя Б.О.Тураева, - приводит к тому, что в процессе действия причины совершается перенос свойств одного объекта (причины) на другой (следствие) [7]. Так происходит передача материи и движения от причины к следствию, перенос структуры объекта, т.е. воспроизведение в процессе причинного отношения структуры причины в структуре следствия. Для всех форм отражения в той или иной степени характерно такого рода структурное соответствие объектов, устанавливающееся в процессе причинноследственной связи. Одним из простых видов структурного соответствия является отношение наглядного копирования. Таково, например, отношение фотографии к объекту отражения. При фотографировании внешняя структура предмета, отражая лучи света, передаётся структуре светового потока, а эта последняя запечатлевается на поверхности фотобумаги. Конечно, структурное соответствие часто носит более абстрактный и не столь явный характер. Например, пространственная структура в виде цифровых носителей при её проигрывании воспроизводится в звуках, т.е. в определённой временной последовательности колебаний воздуха.

Опирающийся на причинно-следственную связь перенос структуры является важнейшим условием формирования субъективных образов в сознании человека, в частности чувственных восприятий. Имеется, например, определённая аналогия между фотографическим изображением и зрительным образом, возникающим в сознании субъекта. Так, световой поток, отразившись от предмета, в неоднородности своего распределения воспроизводит структуру предмета. Попадая на сетчатку глаза, этот неоднородный поток света вызывает в ней определённые изменения, которые соответствуют характеру взаимодействия. Информация о внешних явлениях передаётся в мозг, в результате деятельности которого и возникает зрительное изображение предмета.

Как отмечал В.А.Лекторский, - единство субъекта и объекта, мышления и того, о чём мыслится в теории познания получает научное объяснение благодаря правильно понятой практике, обращение к которой привело к открытию реальной связи познания с объективным миром [8].

Практика направляет научное познание к получению новых знаний о настоящем и будущем, стимулируя их к постоянному поиску.

Практика таким образом выступает как один из факторов, детерминирующих идеальную деятельность, которым обусловлен активный, творческий характер познания, его целенаправленность и предметность. Познание во всех его формах, начиная с чувственного восприятия, формируется в процессе активной деятельности человека с материальными и духовными объектами.

Наиболее существенный признак активности знания состоит в том, что оно отображает объект в связи и в соответствии с задачами, потребностями и целями познающего субъекта. Иначе и быть не может, так как само знание возникло, сформировалось и развивалось на основе человеческой деятельности, требования которой и находят своё выражение в задачах, потребностях и целях субъекта.

Творческое воображение, способность предвидения (опережающего отражения), ценности и нормы, использование абстракций и идеализаций, создание целого мира искусственных предметов-посредников и т.п. вот те компоненты, которые выражают активный характер человеческого познания, вырастающего из практической деятельности человека [9].

В частности, в восприятии содержатся элементы творческого воображения, вносящие в актуальный образ элементы прошлого и будущего. Вместе с тем воображение может выступать независимо от восприятия, в формах более свободных, где преобладает продуктивный момент.

В познании воображение выполняет огромную эвристическую роль, содействуя выдвижению новых смелых гипотез, 
формированию идеализированных объектов научных теорий, позволяя наглядно представить следствия принимаемых допущений и т.п.

Активность субъекта в процессе познания оказывается необходимым условием для раскрытия сущности исследуемого объекта для выявления его внутренних свойств и связей.

Проникновение человеческого познания в сущность исследуемого объекта, воспроизведение в идеальной форме присущих ему необходимых свойств и связей, законов его функционирования и развития предполагает изменение не только самого объекта, но и возникающих в процессе его отражения идеальных образов [10], создание новых идеальных конструкций, не имеющих непосредственных аналогов объективной действительности, конструкций, которые будучи субъективными формами познавательной деятельности, лишь опосредовано отражают её. Однако всегда следует помнить о том, что все даже наиболее абстрактные конструкции человеческого ума - в конечном итоге есть не что иное как отражение действительности.

Активный практический характер человеческого познания наиболее выпукло проявляется в том, что в целях познания люди создают особые объекты - приборы, инструменты, экспериментальные установки и т.п., которые, с одной стороны, воплощают в себе знания человека о сторонах и свойствах объективного мира, и, с другой стороны, служат для более глубокого отображения сущности вещей и явлений. Хотя в ходе познания порой может иметь место и воздействие на естественный объект - это происходит, например, в процессе экспериментирования, - но это воздействие связано не с изменением познавательных характеристик объекта, а лишь с созданием условий их лучшего обнаружения.

Осуществление акта познания как специфически человеческого отражения, воспроизведение существенных характеристик объекта предполагает не только активную деятельность субъекта с предметом, но и создание им - не как природным индивидом, а как общественным человеком, т.е. в кооперации с другими людьми - определённой системы «искусственных» предметов, опосредующих процесс отражения и несущих в себе познавательные нормы, эталоны, выступая в функции средств познания эти предметыпосредники обладают специфической особенностью. С одной стороны, их назначение состоит в том, чтобы давать субъекту возможность познавательного отражения характеристик тех объектов, которые существуют независимо от них. С другой стороны, сами посредники являются своеобразными объектами, которые обладают собственными особенностями, имеют внутренние связи, предполагают определённые способы оперирования с ними и существуют во внешней, опредмеченной форме. Но это значит, что осуществление познавательного акта предполагает со стороны субъекта не только умение соотносить предметыпосредники с познаваемыми объектами. Нужно также владеть способами оперирования той специфической реальностью, которой являются сами социально-функционирующие искусственные предметы.

В современной концепции научного предвидения важное место занимает решение вопроса о критериях достоверности научной теории вообще, научного предвидения, в частности. В существующей литературе встречаются различные подходы по данному вопросу. Принято считать, что первым критерием, по которому можно судить об истинности научных предположений, является известное ещё Д.Юму и И.канту требование соотнесения этих предположений с опытом. Если в чувственном опыте невозможно указать какиелибо объекты, которое это понятие подтверждает, то оно лишено значения, оно является неверной, пустым звуком. В западно-европейской философии XX века, в частности у позитивистов Венского кружка, это требование получило название принципа верифицируемости: научные понятия, предположения, теории имеют значение, если они эмпирически проверямы.

В литературе по методологическим проблемам науки встречаются и другие мнения. Так, Карл Поппер выступил с идеей критического рационализма. Критицизм Поппер считает основным методом науки и наиболее рациональной стратегией поведения учёных. В работе «логика и рост научного знания» он пишет: «Я обнаружил, что те из моих друзей, которые были поклонниками Маркса, Фрейда и Адлера, находились под впечатлением их явной объяснительной силы. Казалось, эти теории способны объяснить практически всё, что происходит в той области, которую они описывали. Изучение любой из них как будто бы приводило к полному духовному перерождению или к откровению, раскрывающему наши глаза на новые истины, скрытые от непосвящённых. Раз наши глаза однажды были раскрыты, вы будете видеть подтверждающие примеры всюду: мир полон верификациями теории. Всё, что происходит, подтверждает её. Поэтому истинность теории кажется очевидной, и сомневающиеся в ней выглядят людьми, отказывающимися признать очевидную истину, либо потому, что она несовместима с их классовыми интересами, либо в силу присущей 
им подавленности, не понятой до сих пор и нуждающейся в лечении» [11].

Размышляя над этой ситуацией, Поппер пришёл к выводу, что нетрудно получить верификации, эмпирические подтверждения почти любой умело скроенной теории. Но подлинно научные теории должны выдерживать более серьёзную проверку. Они должны допускать рискованные предсказания, т.е. из них должны выводиться такие факты и наблюдаемые следствия, которые, если они не наблюдаются в действительности, могли бы опровергнуть теорию. Не верифицируемость, которую выдвигали члены Венского кружка, служит, по мнению Поппера, критерием научности. Критерием демаркации научных теорий, предсказаний на верные и неверные является фальсифицируемость опровержимость любого утверждения, относимого к науке.

По мнению Поппера, настоящая наука не должна бояться опровержений: рациональная критика и постоянная коррекция фактами является сутью научного познания. Поппер предложил достаточно динамичную концепцию научного знания как непрерывного потока предположений (гипотез) и их опровержений. Развитие науки он уподобил дарвиновской схеме биологической эволюции. Постоянно выдвигаемые гипотезы и теории должны проходить строгую селекцию в процессе рациональной критики и попыток опровержения, что соответствует механизму естественного отбора в биологическом мире. Выживать должны только «сильнейшие теории», но и они не могут рассматриваться как абсолютные истины. Всё человеческое знание имеет предположительный, относительный характер, в любом его фрагменте можно усомниться, и любые положения должны быть открыты для критики.

\section{Conclusion}

Любые научные положения, в том числе и предполагаемые могут быть связаны с практикой через свой эмпирический или теоретический базис. Поэтому о степени правильности знаний можно судить уже по их отношению к тому или иному базису.

Различаются эмпирическая и теоретическая достоверность, соответствующая двум уровням научного познания, эмпирическому (чувственному) и теоретическому (абстрактному). Если эмпирическая достоверность в основном определяется данными чувственного опыта, то теоретическая достоверность - рациональными элементами и тождественна очевидности, которая, однако не просто умозрительна, а обусловлена философскими истинами, входящими в теоретический базис. Эти истины, как известно, проверяются практикой.

Проблема достоверности научного предвидения всё ещё остаётся дискуссионной, требующей дополнительного научного анализа.

\section{References:}

1. Karimov IA (1995) Rodina svjashhenna dlja kazhdogo. - Tashkent, Uzbekistan, 1995.

2. Tulenova K (1998) Predvidenie i real'nost'. Tashkent, 1998.

3. Abdullaeva MN (1982) Adekvatnoe otrazhenie na ehmpiricheskom urovne. Tashkent, «Fan», 1982.

4. Zvedenyuk AV (1989) Stanovlenie nauchnogo znaniya. Tashkent, «Fan», 1989.

5. Chernik VG (1988) Dialekticheskij perekhod v razvitii nauki. Tashkent, «Fan», 1988.

6. Ivanova KI (1974) Princip prichinnosti v sisteme principov nauchnogo poznaniya. Tashkent, «Fan», 1974.
7. Turaev BO (1992) Prostranstvo. Vremya. Razvitie. Tashkent, «Fan», 1992.

8. Lektorskij VA (1980) Sub"ekt. Ob"ekt. Poznanie. - Moscow, «Nauka», 1980.

9. Spirkin AG (1972) Soznanie i samosoznanie. Moscow, 1972.

10. Tulmin S (1984) Chelovecheskoe ponimanie. Moscow, «Progress», 1984.

11. Popper K (1985) Logika i rost nauchnogo znaniya. Moscow: Progress, 1985. 